\title{
TRABALHO DECENTE E TRABALHO DIGNO - NORMAS INTERNACIONAIS QUE VEDAM O RETROCESSO DO DIREITO DO TRABALHO
}

\author{
Ynes da Silva Felix ${ }^{1}$ \\ Antônio Leonardo Amorim ${ }^{2}$
}

\section{Resumo}

Nesse trabalho vamos trazer conceitos de trabalho decente e trabalho digno a partir das normas internacionais que o Brasil é signatário, bem como a forma de proteção no plano internacional. Será demonstrado como o Brasil vem seguindo esses ditames internacionais e quais os efeitos da não observância dessas normas, bem como das influencias no direito do trabalho brasileiro dos conceitos trazidos pelo trabalho decente e trabalho digno. Para realizar a presente pesquisa vamos fazer uso do método indutivo e dedutivo, de pesquisa bibliográfica e documental, com uso da doutrina sobre as normas internacionais do trabalho decente e digno.

Palavras-chave: Trabalho Decente; Trabalho Digno; Normas Internacionais; Retrocesso; Direito do Trabalho.

\section{DECENT WORK AND WORTHY WORK - INTERNATIONAL STANDARDS THAT VIEW THE BACKWARDS OF LABOR LAW}

\begin{abstract}
In this work we will bring concepts of decent work and decent work from the international norms that Brazil is a signatory, as well as form international protection. It will be demonstrated how Brazil has following these international dictates and what the effects of non-observance of these norms, as well as of the influences in the Brazilian labor law of the concepts brought by decent work and decent work. To carry the present research we will make use of the inductive and deductive method bibliographical and documentary research, using the doctrine on the international norms of decent and decent work.
\end{abstract}

Keywords: Decent Work; Decent Work; International Standards; Retraction; Labor Law.

\section{INTRODUÇÃO}

Este trabalho tem por objetivo trazer o conceito de trabalho decente conforme norma da Organização Internacional do Trabalho, bem como o conceito de trabalho digno sob a mesma perspectiva.

\footnotetext{
${ }^{1}$ Doutora em Direito pela Pontifícia Universidade Católica de São Paulo, Diretora da Faculdade de Direito da Universidade Federal de Mato Grosso do Sul.

${ }^{2}$ Mestrando em Direito na Universidade Federal de Mato Grosso do Sul.
} 
O trabalho decente é forma de trabalho em condições que priorizam o ser humano na realização do seu trabalho, de igual modo, o trabalho digno é a realização do trabalho em condições dignas.

Foi no ano de 2003, o então presidente à época Luiz Inácio Lula da Silva assinou com a OIT o memorando de entendimento, que trouxe para o plano nacional o trabalho decente, a ser implementado em conformidade com a Agenda Nacional de Trabalho Decente.

O trabalho digno modo também tem seu registro na Organização Internacional do Trabalho, o qual foi ratificado pelo Brasil e implementado no ordenamento jurídico nacional.

Dessa forma, a presente pesquisa, será desenvolvida a partir do método indutivo e dedutivo, objetiva, por meio de material bibliográfico e documental, demonstrar quais os conceitos de trabalho decente e trabalho digno, como normas internacionais mandamentais.

Essa pesquisa foi dividida em três partes. A primeira traz o conceito de trabalho decente, e sua forma de realização, a segunda traz o conceito de trabalho digno, e como deve ser operado no Brasil. E a terceira parte será feito um paralelo dessas normas internacionais com o retrocesso da relação de trabalho.

Pois bem, considerando tais explanações fazem-se necessários verificar o que a doutrina vem relatando sobre trabalho decente e trabalho digno, bem como o retrocesso da relação de trabalho, seus efeitos na comunidade.

Por essa razão, faz-se necessário trazer a discussão esse tema que é demasiadamente importante para a sociedade.

\section{TRABALHO DECENTE}

O trabalho decente começou a ser desenhado pela Organização Internacional do Trabalho no ano de 1992, que por saber da necessidade de promover a igualdade de acesso ao trabalho produtivo das pessoas e na igualdade de oportunidades, deu início a um conceito com base na proteção social do trabalhador.

Para DRUCK (2011, p. 46) trabalho decente é "trabalho produtivo e adequadamente remunerado, exercido em condições de liberdade, equidade e segurança, sem quaisquer formas de discriminação, e capaz de garantir uma vida digna a todas as pessoas que vivem de seu trabalho". 
O conceito de trabalho decente também é trazido pelo Plano Nacional do Trabalho

Decente (Brasil, 2010, p.111). Textualmente:

Trabalho Decente é uma condição fundamental para a superação da pobreza, a redução das desigualdades sociais, a garantia da governabilidade democrática e o desenvolvimento sustentável. Em inúmeras publicações, o Trabalho Decente é definido como o trabalho adequadamente remunerado, exercido em condições de liberdade, equidade e segurança, capaz de garantir uma vida digna. Para a Organização Internacional do Trabalho (OIT), a noção de trabalho decente se apoia em quatro pilares estratégicos: a) respeito às normas internacionais do trabalho, em especial aos princípios e direitos fundamentais do trabalho (liberdade sindical e reconhecimento efetivo do direito de negociação coletiva; eliminação de todas as formas de trabalho forçado; abolição efetiva do trabalho infantil; eliminação de todas as formas de discriminação em matéria de emprego e ocupação); b) promoção do emprego de qualidade; c) extensão da proteção social; d) diálogo social.

No ano de 2003 a Organização Internacional do Trabalho com o então presidente Luiz Inácio Lula da Silva assinaram a agenda de trabalho decente, que veio a ser promovida no Brasil em 2006.

O conceito de trabalho decente tem como objetivo trazer para o plano nacional o reconhecimento da liberdade, igualdade, segurança e equidade do emprego realizado de forma produtiva.

A agenda segue a prioridade em três segmentos (Brasil, 2010, p. 1): “a geração de melhores empregos com igualdade de oportunidades e de tratamento; a erradicação do trabalho escravo e eliminação do trabalho infantil, em especial em suas piores formas; e o fortalecimento dos atores tripartites e do diálogo social como um instrumento de governabilidade democrática”.

É necessário que para a realização do trabalho decente, conforme exposto pela OIT, o trabalho a ser adequadamente remunerado, sobre essa perspectiva, a doutrina de GOSDAL (2006, p. 98) diz que:

É possível compreender-se que o salário mínimo, que constitui a remuneração de boa parte da população do país, garante as condições mínimas para uma vida saudável? Ou o conceito refere-se a um dever-ser abstrato, não à realidade concreta? E a possibilidade de pagamento do adicional de insalubridade em razão da existência de condições insalubres de trabalho? Não seria o caso de se proibir, então, qualquer trabalho em condições insalubres? Ou de se obrigar à melhoria das condições de trabalho, com a adoção de medidas de proteção coletiva dos trabalhadores, mesmo que tornando mais elevados os custos de produção?

O trabalho decente pode ter sua definição como sendo meio de exercício de trabalho em conformidade com a vida digna, por isso tratamos de ambos os conceitos nesse trabalho. 
Observa GOSDAL (2006, p. 99) que "a dignidade no trabalho é uma categoria axiológica aberta, que não pode ser fixada de modo definitivo, porque precisa ser permanentemente definida pelas situações concretas". Pois bem, o conceito de trabalho decente por vezes se alterará no tempo, em razão das mudanças sociais, e isso exige uma atualização constante desse conceito, sempre observando a vedação ao retrocesso.

Além disso, deve o trabalho decente pelo conceito trazido pela OIT assegurar o direito ao empregado da realização de trabalho em condições dignas, para que então possa ser chamado de trabalho decente.

Para MOCELLIN (2009, p. 3), "o negativo de trabalho decente seria trabalho precário". Desse modo, o conceito de trabalho decente é por via transversa o que não pode acontecer, pois caso isso ocorra, estaremos diante de violações às normas internacionais que o Brasil é signatário.

Em contramão ao exposto trabalho decente tem o trabalho degradante ou em condições degradantes, o qual afronta esse memorando de entendimento assinado pelo Brasil, bem como a Declaração Universal de Direitos Humanos a qual somos signatários.

A perspectiva do trabalho degradante está intimamente ligada ao capitalismo que traz como seu corolário a obtenção de lucros e larga escala, pouco se importando com a condição do trabalho do ser humano.

O trabalho decente deve ser visto também como meio de implementação de um mínimo de norma a ser observada no direito do trabalho, e com isso temos o viés da dimensão moral do trabalho que na perspectiva de Fabrício Maciel (2006, p. 319) é a noção do que é bom e do que é mau para a vida do trabalhador. Assim dispõe:

[...] um pano de fundo valorativo que estabelece os bens imateriais e as noções do que é bom e do que é mau, e, consequentemente, do que é uma boa vida que deve ser valorizada por todos, o que pode gerar distinções e hierarquias.

Desse modo, como vimos, o trabalho decente é aquele realizado em condições adequadas que possa proporcionar ao ser humano a plena realização do emprego produtivo.

\section{TRABALHO DIGNO}

O trabalho digno é direito fundamental do trabalhador, e para entender o que é será necessário demonstrar historicamente o surgimento desses direitos aos trabalhadores. $\mathrm{Na}$ 
segunda metade do século $\mathrm{XX}$, o direito fundamental ao trabalho conseguiu o status de constitucionalização, e foram nas constituições do México de1917 e na da Alemanha em 1919.

No Brasil a forma de constitucionalização dos direitos fundamentais do trabalho teve sua implementação de forma progressiva e regressiva ao mesmo tempo, na Constituição de 1824 muito embora dissesse que as mulheres e analfabetas não poderiam participar a vida política do país, trouxe o direito à liberdade da realização do trabalho por meio de ofícios e profissões.

A Constituição de 1891 trouxe a possibilidade da liberdade de associação e reunião. De igual modo, a Constituição Federal de 1934 inovou com a constitucionalização de direitos sociais.

Segundo a doutrina de José Afonso da Silva (2000, p. 84) “a Constituição de 1934 foi a primeira a introduzir normas jurídicas referentes à ordem econômica e social, apesar de a maioria delas ainda se revestir de caráter programático".

Muito embora a Constituição de 1934 tivesse introduzido direitos sociais aos cidadãos, teve sua eficácia cessada em 1935 com o Estado de Sítio de Getúlio Vargas.

Na Constituição de 1937 surgiu o sindicato único e o imposto sindical obrigatório. Foi na Constituição de 1937 que a Consolidação das Leis do Trabalho foi aprovada, por meio do Decreto Lei n. ${ }^{\circ} 5.452$, de $1^{\circ}$ de maio de 1943.

A primeira Constituição a tratar da dignidade da pessoa humana expressamente foi a de 1946, que se referiu à dignidade da pessoa humana apenas quanto ao valor social do trabalho, para que fosse efetivada a existência digna de vida.

Porém essa grande conquista histórica teve cessação no ano de 1964, quando então foi instituído no Brasil o Golpe Militar de 1964. Após esse período a Constituição de 1967 trouxe a previsão do Tribunal Superior do Trabalho e dos Tribunais Regionais do Trabalho.

A Constituição Federal de 1988 trouxe uma nova ordem constitucional para o país, e trouxe como princípios a dignidade da pessoa humana, o valor social do trabalho e a justiça social. Sobre essa nova ordem constitucional Mauricio Godinho Delgado (1992, p. 45-46) dispõe do seguinte entendimento. Vejamos:

A nova Constituição da República inscreve-se como a mais substantiva Carta de Direitos produzida pelo constituinte do País, em toda a história política brasileira. Até topograficamente, a Carta de 88 evidencia a prevalência da pessoa humana em seu interior, certificando em seu frontispício, capítulos e normas iniciais, direitos de caráter individual e social, que ocupam o espaço aberto por todas as Cartas 
anteriores exclusivamente às entidades estatais da União, Estados, Distrito Federal e Municípios. É relevante, social e politicamente, essa distinção no tratamento jurídico, incompreensíveis o fato e o conceito de cidadania sem o instrumental e estatuto jurídico hábeis a lhes conferir consistência prática. O encouraçamento jurídico da noção de cidadania é aspecto importante à sua efetiva configuração social.

Foi a Constituição de 1988 que trouxe o patamar mínimo civilizatório para o direito do trabalho, que em seu art. $7^{\circ}$, inicia com um rol de direitos mínimos trabalhistas assegurados, diz a CF "são direitos dos trabalhadores urbanos e rurais, além de outros que visem à melhoria de sua condição social".

O conceito de trabalho digno para a Organização Internacional do Trabalho (2010, p. 1). Vejamos:

O conceito de trabalho digno resume as aspirações do ser humano no domínio profissional e abrange vários elementos: oportunidades para realizar um trabalho produtivo com uma remuneração equitativa; segurança no local de trabalho e protecção social para as famílias; melhores perspectivas de desenvolvimento pessoal e integração social; liberdade para expressar as suas preocupações; organização e participação nas decisões que afectam as suas vidas; e igualdade de oportunidades e de tratamento para todas as mulheres e homens.

Refletir sobre o que é trabalho digno e meios de programa-lo na ordem jurídica brasileira é uma forma de obedecer às normas internacionais que dão orientações ao mínimo de direitos que devem ser assegurado aos empregados.

Como se pode observar do conceito de trabalho digno pela OIT, é a forma de condição digna ao ser humano, que ao laborar deve ter oportunidade para realizar um trabalho produtivo e com remuneração equivalente e justa.

Muito embora esse conceito possa por vezes confundir-se com o do trabalho decente, não é o caso, acreditamos que ambos se complementam entre si, já que o primeiro traz as aspirações do ser humano como profissional e o trabalho decente é a condição fundamental para a superação da pobreza.

Na Constituição Federal de 1988 , em seu art. $7^{\circ}$, IV, temos o que é considerado de mínimo de remuneração para os empregados. Vejamos:

Art. $7^{\circ} .(\ldots)$

IV - salário mínimo, fixado em lei, nacionalmente unificado, capaz de atender a suas necessidades vitais básicas e às de sua família com moradia, alimentação, educação, saúde, lazer, vestuário, higiene, transporte e previdência social, com reajustes periódicos que lhe preservem o poder aquisitivo, sendo vedada sua vinculação para qualquer fim. 
Muito embora a doutrina considere essa norma como o mínimo assegurado pela Constituição, ainda não atende aos ditames do conceito de trabalho digno exposto pela OIT, visto que o salário mínimo brasileiro hoje não é suficiente a atender a equitativa frente ao trabalho.

Segundo o mandamento da OIT sobre trabalho digno, deve os países assegurar a forma de trabalho que seja responsável pelo desenvolvimento da perspectiva do desenvolvimento pessoal do trabalhador.

De igual modo, o trabalho como forma digna do trabalhador deve ser suficiente para a integração desses no meio social, e isso muito importante para a vida do empregado.

No mesmo ínterim, deve os Estados signatários oportunizar tratamento igual entre homens e mulheres, pois, isso também é forma de interação e trabalho digno, conforme mandamento da Organização Internacional do Trabalho.

Na doutrina de Gabriela Neves Delgado (2006, p. 55) não há outra forma de concretização dos direito à vida digna se não for promovido o trabalho digno. Vejamos:

\footnotetext{
Não há como se concretizar o direito à vida digna se o homem não for livre e tiver acesso ao direito fundamental ao trabalho também digno. Da mesma forma, não há possibilidade real do exercício do trabalho digno se não houver verdadeira preservação do direito fundamental à vida humana digna.
}

Sob esses mandamentos da OIT, como reflexo direto na vida do empregado extraimos que a dignidade do trabalho no qual o ser humano se submente é por si só revelador de sua identidade social, pois nele o empregado exerce sua liberdade conforme sua consciência, bem como de conseguir dispor da sua plenitude, e, por conseguinte irá desenvolver seu potencial.

\section{NORMAS INTERNACIONAIS QUE VEDAM O RETROCESSO DA RELAÇÃO DE} TRABALHO

As Cartas Internacionais visam resguardar direitos humanos e sociais, e impõe aos Estados signatários o seguimento desse entendimento, e os mandamentos que tratam de direito do trabalho em sua maioria são expedidos pela OIT (Organização Internacional do Trabalho).

Sobre a forma como o Brasil se inseriu no processo de redemocratização, segundo Flávia Piovesan (2000, p. 100) ocorreu da seguinte forma. Vejamos: 
No caso brasileiro, o processo de incorporação do Direito Internacional dos Direitos Humanos e de seus importantes instrumentos é consequência do processo de democratização, iniciado em 1985. O marco inicial do processo de incorporação de tratados internacionais de direitos humanos pelo Direito Brasileiro foi à ratificação, em 1989, da Convenção contra a Tortura e Outros Tratamentos Cruéis, Desumanos ou Degradantes. A partir desta ratificação, inúmeros outros importantes instrumentos internacionais de proteção dos direitos humanos foram também incorporados pelo Direito Brasileiro, sob a égide da Constituição Federal de 1988. Assim, a partir da Carta de 1988, foram ratificados pelo Brasil: a) a Convenção Interamericana para Prevenir e Punir a Tortura, em 20 de julho de 1989; b) a Convenção sobre os Direitos da Criança, em 24 de setembro de 1990; c) o Pacto Internacional dos Direitos Civis e Políticos, em 24 de janeiro de 1992; d) o Pacto Internacional dos Direitos Econômicos, Sociais e Culturais, em 24 de janeiro de 1992; e) a Convenção Americana de Direitos Humanos, em 25 de setembro de 1992; f) a Convenção Interamericana para Prevenir, Punir e Erradicar a Violência contra a Mulher, em 27 de novembro de 1995.

O Brasil apenas se compromete a assegurar a aplicabilidade das normas internacionais apenas após a assinatura do respectivo tratado ou documento internacional, bem como a sua internalização no ordenamento jurídico por meio de lei, ou programa nacional.

A Organização Internacional do Trabalho é órgão da Organização das Nações Unidas, e tem como função expedir normas que asseguram a forma de realização de trabalho.

Nos ensinamentos de Paulo Henrique Gonçalves Portela (2015, p. 463) os objetivos da OIT são. Vejamos:

A OIT tem como objetivo principal estabelecer padrões internacionais mínimos para as relações trabalhistas e garantir melhores condições de trabalho em todo mundo, com vistas a promover a dignidade da pessoa humana, o bem estar geral e a justiça social e, assim, contribuir para a paz mundial.

Corroborando o conceito acima exposto, SUSSEKIND (1999, P. 120) informa que a Organização Internacional do Trabalho visa também orientar as políticas legislativas para os países membros. Textualmente:

a sociedade das nações tem por objetivo estabelecer a paz universal, que não pode ser findada senão sobre a base da justiça social;

existem condições de trabalho que implicam, para um grande número de pessoas, injustiças, miséria e privações;

a não adoção por uma ação qualquer de um regime de trabalho realmente humanitário é um obstáculo aos esforços dos demais desejosos de melhorar a sorte dos demais trabalhadores nos seus próprios países.

Vale ressaltar que o Brasil é membro fundador da OIT e dela participa desde sua primeira reunião. 
Neste raciocínio, podemos entender que as normas internacionais na verdade tratam de mandamentos que tendem a proteger as pessoas do poder arbitrário dos Estados.

Para Nilmário Miranda (2004, p. 4) os conceitos trazidos pela OIT do trabalho decente e do trabalho digno são formas de resgate da cidadania do se humano. Textualmente:

[...] o verdadeiro resgate da cidadania é o direito ao trabalho, e ao trabalho decente, ao trabalho digno. Neste sentido, a OIT tem sido uma parceira inestimável da humanidade, desde que foi criada, em 1919, do Brasil, desde 1950, quando passou a trabalhar aqui, atingindo o nó do problema do trabalho no Brasil, quer o trabalho infantil, quer o trabalho forçado, escravo, obrigatório.

Desde a criação da OIT, percebemos que como órgão nacional de proteção do trabalho teve no Brasil grandes avanços na proteção dos direitos dos trabalhadores, e retroceder como é o estado atual do país vai de encontro com os objetivos e proteção então regulamentados.

Na doutrina de Joaquim Herrera Flores (2009, p. 83-84) temos o seguinte entendimento sobre ordem social justa. Vejamos:

A liberdade não vai realizar-se por si própria. Sempre exigirá uma ordem social justa na qual se deem condições materiais precisas para consegui-la. Porém, reivindicar a integralidade e a inter-relação entre liberdade e igualdade parece ficar fora do raciocínio. É o impuro, o híbrido, o mesclado. Podemos pensar, preceituar e opinar livres de qualquer condicionamento social e, além disso, com todas as garantias, de estatais imagináveis. Mas, dispor de condições materiais para desfrutar de saúde, de um ambiente limpo ou de uma moradia digna nos obriga, segundo tal ideologia, a incluir elementos estranhos à pretendida pureza do jurídico-formal. O sistema de valores dominante aposta em favor de uns direitos e renega outros.

As normas internacionais, como é o caso aqui demonstrado, trabalho decente e trabalho digno, ambas trazidas pela Organização Internacional do Trabalho, são formas de garantia de acesso e melhor condição para o trabalho humano.

Atualmente no Brasil tramita no Congresso Nacional a denominada "Reforma Trabalhista", que é registrada pelo Projeto de Lei (PL) 6787/2016, o qual altera substancialmente a forma do trabalho,.

De igual modo, em março de 2017, entrou em vigor no Brasil a Lei n. ${ }^{\circ}$ 13.429/2017, que trouxe a regulamentação da terceirização, tema esse que era conflituoso no ordenamento jurídico brasileiro.

A doutrina brasileira em sua maioria considera essa regulamentação vigente e o projeto de reforma trabalhista como retrocesso da relação de trabalho. 
Ressaltamos que o nosso objetivo nesse trabalho não é rebater todos os pontos de retrocesso de normas trabalhistas tendentes pela reforma trabalhista, bem como pela recente regulamentação da terceirização, mas sim demonstrar o que é o trabalho decente e trabalho digno, e o porquê dessas normas internacionais se manterem em efetividade no Brasil, para que então essas normas tendentes à redução de direitos trabalhistas possam ser refutadas.

Como mencionado, existe uma lei vigente no Brasil que flexibiliza direitos trabalhistas garantidos que é a possiblidade de terceirização, e outras em trâmite no Congresso Nacional que tendem aumentar essa flexibilização que é a reforma trabalhista.

Por anos os trabalhadores lutaram para conseguir o patamar de direitos mínimos assegurados constitucionalmente, como demonstramos no histórico do trabalho digno.

Sobre a possibilidade de flexibilização Gabriela Neves Delgado (2006, p. 240) traz o seguinte entendimento. Vejamos:

É por isso que as propostas de desregulamentação e de flexibilização trabalhistas, fenômenos típicos do Estado Poiético, com vistas a atender às exigências de mercado, além de romperem com a diretriz protetiva do Direito do Trabalho, também fragilizam o sentido de dignidade que deve ser inerente a qualquer tipo de prestação de serviços, eis que é valor nuclear para a humanidade.

Em complemento ao pensamento DELGADO (2006, p. 241). Assim dispõe:

Considera-se, todavia, que as mudanças jurídicas a serem implementadas devem fundamentar-se na lógica finalística originária do Direito do Trabalho. Ou seja, qualquer mudança legislativa deverá propor a melhoria das condições de trabalho em favor do obreiro, e não a precarização da prestação de serviços, desenvolvida conforme interesse privado e egoístico do mercad. Além disso, também deverá alargar a proteção jurídica aos trabalhadores não empregados, com base numa visão humanitária e universal do Direito do Trabalho.

As normas trabalhistas devem seguir a tendência de aumentar mais garantias aos empregados, e não o movimento contrário, pois nesse caso estaríamos diante de um retrocesso social.

Para NASCIMENTO (2002, p. 219) o trabalho deve ser visto pelo capitalismo não apenas como meio de produção, mas também no sentido solidário. Textualmente:

O significado do trabalho na realidade contemporânea não se prende às amarras de uma limitação meramente produtiva ou econômica e encerra um outro sentido, próprio de uma sociedade solidária - sociedade em que a exclusão é concebida como desvio social, que exige correção pelos seus próprios membros e instituições. Nessa compreensão, de corte histórico-axiológico e humanístico, o trabalho eleva-se como uma das fórmulas de inserção social, como meio que deve ser assegurado à pessoa, de desempenhar um papel em sua comunidade.

Revista Brasileira de Direito Internacional | e-ISSN: 2526-0219 | Brasília | v. 3 | n. 1 | p. 21 - 35 | Jan/Jun. 2017. 
Por essa razão, as normas tendentes a regulamentar direito do trabalho devem observar as normas internacionais que o Brasil já ratificou, em especial o que é trazido pelo trabalho decente e trabalho digno pela Organização Internacional do Trabalho.

Ainda sobre o retrocesso da relação do trabalho, em análise a reforma trabalhista (ROCHA, 2016, p. 4) diz que "olhando para o resumo da obra, a ponte para o futuro parece mais um túnel escuro para aqueles que um dia sonharam com uma sociedade mais igualitária e sem pobreza. Trata-se de uma ponte para o passado e um passo para o abismo".

A criação de novos paradigmas de produção, em razão do contexto da economia global, que é o proposto pela recente lei da terceirização, faz com que o capital reprima o direito do trabalho, precarizando e flexibilizando normas trabalhistas, para que tenhamos mão de obra barata e atuando em desacordo com as normas internacionais da OIT.

Nos ensinamentos de Reginaldo Melhado (2006, p. 39) encontramos em síntese um desenvolvimento da forma como se dá a opressão do capitalismo no trabalho. Vejamos:

As novas técnicas de gerenciamento não nascem, porém, como simples fruto de desenvolvimento da ciência. Impõem-nas o processo cada vez mais forte de concentração do capital industrial, do capital mercantil ao capital financeiro, e da tendência da interseção de cada uma destas dimensões. "Se antes os bancos entregavam a terceiros prosaicas tarefas de limpeza, impressão de talonário e transporte de numerário" - descrevia um jornal brasileiro a tempos atrás - "agora vão além: contratam empresas especializadas em serviços financeiros. Nessa nova fase, a terceirização atinge a gestão de fundos de investimento, de cartões de crédito, de riscos de seguros. Sem falar em outras áreas de risco operacional, como a compensação de cheques". Visa, Master Card e outras empresas contratam empresas que se encarregam do processamento eletrônico do seu "dinheiro plástico". Empresas como CardSystem, Uosi, e Cardway (no Brasil) fazem lançamentos contábeis dos cartões e administram o produto, estabelecendo as estratégias de marketing, gerindo as relações com estabelecimentos e outros serviços. A analise de riscos, elemento mais elementar da atividade de uma companhia seguradora e imprescindível para a fixação do custo e portanto do preço de uma apólice passou a ser realizada por empresas especializadas. Nas montadoras japonesas de veículos, como a Toyota, cerca de $75 \%$ de cada unidade são feitos fora da planta industrial da companhia. Ao Estado mínio da onde neoliberal corresponde a empresa mínima. Minimalista em número de empregos a serem gerados através da atividade. Minimalista em termos de custos operacionais e, portanto de direitos e vantagens econômicas asseguradoras aos seus trabalhadores. Minimalistas, enfim, para maximizar sua taxa de lucros.

Nessa situação específica que demonstra a atividade dos bancos, notamos que o único objetivo é o lucro, e em razão disso, investem fortemente na contratação de terceirizados, e com a nova lei de terceirização será feito de forma legítima. 
Como foi exposto sobre o trabalho digno e trabalho decente o Brasil é membro signatário dessas normas internacionais expendidas pela Organização Internacional do Trabalho.

No caso do trabalho decente foi trazido para o plano nacional, foi pelo memorando de entendimento que em 2006 entrou teve sua vigência no Brasil, já o trabalho digno está no plano nacional diversificado nas constituições que vieram tratando timidamente sobre essa condição de trabalho até chegar a se efetivar o trabalho digno da OIT na Constituição Federal de 1988.

Em razão disso, como foi demonstrado existem normas regulamentadas e em vigor no Brasil como é o caso da terceirização pela Lei n. ${ }^{\circ}$ 13.429/2017, bem como o PL n. ${ }^{\circ}$ 6787/2016 que traz a reforma trabalhista, formas essas de flexibilização de direitos, são contrárias as normas internacionais expostas pela Organização Internacional do Trabalho, das quais o Brasil ratificou e trouxe para o plano interno.

Assim, estaríamos diante de uma situação delicada frente às normas internacionais já inseridas no plano nacional, pois essas inicialmente garantem direitos trabalhistas mínimos para que os Estados signatários garantam e as efetivem no plano interno, e mesmo com essas normas em pleno vigor passamos a legislar contrariando as normas internacionais.

Nota-se que além de retrocesso nas relações de trabalho temos também violações diretas a normas internacionais, das quais o Brasil é signatário, como explanado.

A doutrina majoritária de direito internacional, informa que o Estado deve ser responsabilizado quando existir processos que tendem a violar direitos humanos garantidos em cartas internacionais ratificadas pelos estados.

A violação pelo Brasil quando da legislação sobre a terceirização bem como do trâmite de normas que tendem a violar ainda mais direitos trabalhistas humanos é fato ensejador a sua responsabilidade no plano internacional.

Segundo Marcelo D. Varella (2012, p. 402) quando um Estado viola direito internacional no qual se submeteu está sujeito a ser responsabilizado internacionalmente pelo ato, falando ainda em dever de indenizar. Vejamos:

A responsabilidade internacional dos Estados passa por um lento processo de adensamento jurídico no âmbito internacional. A desigualdade entre os estados e os indivíduos, por um longo período de tempo, impediu que o Estado pudesse ser responsabilizado. A imunidade absoluta de jurisdição e, posteriormente, de execução dificulta ainda hoje a efetividade de eventuais reparações de danos. 
O dever de indenizar decorre da existência de uma ação ou omissão do Estado, de um dano e de uma relação causal entre a ação ou omissão e o dano.

O dano deve ser imputado ao Estado, seja porque foi provocado por seus agentes, seja porque o incentivou ou tolerou.

Quando o Brasil começa a legislar no plano nacional sobre reforma trabalhista estamos diante de uma forma direta de violação as normas internacionais, e assim, estaríamos inadimplentes com o que o compromisso assinado.

Em razão da Lei n. ${ }^{\circ}$ 13.429/2017 e do PL n. ${ }^{\circ}$ 6787/2016 serem formas de flexibilizar direitos trabalhistas, o que vai de encontro com as normas internacional, no nosso caso trabalho decente e trabalho digno pode insurgir responsabilidade internacional.

Desse modo, pelos conceitos trazidos e pela doutrina exposta podemos concluir que as normas internacionais devem ser observadas antes mesmo de se criar novas noras no plano nacional, para que então o país não incorra em sanções internacionais por violar compromissos assinados.

\section{CONSIDERAÇÕES FINAIS}

O trabalho decente e trabalho digno são conceitos trazidos pelo direito internacional para o ordenamento jurídico brasileiro, e devem ser observados quando da necessidade de regulamentações de novos direitos, sejam eles para beneficiar ou retroceder direitos já adquiridos.

O objetivo dessa pesquisa era descrever o trabalho decente e o trabalho digno, a partir de conceitos da Organização Internacional do Trabalho, bem como a forma de aplicação desses conceitos no plano nacional.

Nesse diapasão, em razão dos conceitos expostos sobre trabalho decente e trabalho digno, atrelado aos mandamentos internacionais também mencionados, podemos extrair que quando da legislação de normas trabalhistas como é o caso da reforma trabalhista e da terceirização esses conceitos trazidos pelas normas internacionais devem ser observados.

Os conceitos trazidos pelas normas internacionais servem justamente para garantia ao ser humano condições dignas de sobrevivência. $\mathrm{O}$ valor da dignidade do trabalhador é essencial para o exercício desses, sob qualquer, pois é no trabalho que o se humano entrega o seu inexorável tempo de vida. 
Como foi observado no último tópico o Brasil tem normas que violam os conceitos de trabalho decente e trabalho digno, bem como o projeto de reforma trabalhista que tende a retroceder mais ainda direitos já assegurados, e em razão disso, o Brasil estaria descumprindo normas internacionais que concordou em cumprir.

A consequência disso possivelmente será como demonstrado a penalização no plano internacional, porque não pode o Estado assinar um documento mandamental de normas a serem seguidas e depois descumpri-los.

Desse modo, pelos fundamentos cotejados pela doutrina e normas internacionais, conclui-se que os conceitos de trabalho decente e trabalho digno de forma direta influenciam na forma como devem ser as futuras legislações, pois essas normas internacionais vedam o retrocesso na relação de trabalho.

\section{REFERÊNCIAS}

BRASIL. Constituição (1988).

BRASIL. Ministério do Trabalho e Emprego. Plano Nacional de Trabalho Decente. Brasília, 2010. Disponível em: <www.mte.gov.br/antd/programa_nacional.asp>. Acesso em 15 de mai. 2017.

DELGADO. Mauricio Godinho. Curso de Direito do Trabalho. Salvador: LTR. $8^{\text {a }}$ edição. 2010.

DELGADO. Maurício Godinho. Direito do Trabalho e Modernização Jurídica. Brasília: Consulex, 1992.

DELGADO. Gabriela Neves. Direito Fundamental ao Trabalho Digno. Salvador: LTr, 2006.

DRUCK, Graça. Trabalho, precarização e resistências: novos e velhos desafios?. CADERNO CRH, Salvador: v. 24, p. 37-57, 2011.

FLORES. Joaquín Herrera. A (re)invenção dos direitos humanos. Floriamópolis: Boiteux, 2009.

GOSDAL, T. C. Dignidade do trabalhador: um conceito construído sob o paradigma do trabalho decente e da honra. 2006. 195f. Tese (Doutorado em Direito) - Programa de PósGraduação em Direito, Universidade Federal do Paraná. Curitiba, 2006. Disponível em: <http://dspace.c3sl.ufpr.br/dspace/bitstream/handle/1884/4675/THEREZA\%20CRISTINA20 GOSDAL.PDF;jsessionid=F7574BEF17D81611DD6688EE7671C2AC?sequence>. Acesso em 15 de mai. 2017. 
LISBOA. Organização Internacional do Trabalho. Trabalho Digno Para Todos. Lisboa, $2010 . \quad$ Disponível em: <http://www.ilo.org/public/portugue/region/eurpro/lisbon/html/portugal_visita_guiada_02_pt. htm>. Acesso em 15 de mai. 2017.

MIRANDA. Nilmário. In: Fórum internacional de direitos humanos e direitos sociais realizado pelo TST. São Paulo: LTr, 2004.

MELHADO. Reginaldo. Metamorfose do capital e do trabalho. Relações de poder, reforma do Judiciário e competência da justiça laboral. São Paulo: LTr, 2006.

NASCIMENTO. Marilza Geralda do. O trabalho como valor: afirmação e crise em perspectiva tridimensional, 2002, 244f. Dissertação (Mestrado em Filosofia do Direito) Faculdade de Direito - Universidade Federal de Minas Gerais. Belo Horizonte, 2002.

OIT - ORGANIZAÇÃO INTERNACIONAL DO TRABALHO. Agenda Nacional do Trabalho Decente. Brasília, 2006. Disponível em: <http://www.oitbrasil.org.br/sites/default/files/topic/decent_work/doc/agenda_nacional_trabal ho_decente_536.pdf >. Acesso em: 12 mai. 2017.

PIOVESAN. F. Direitos Humanos Globais, Justiça Internacional e o Brasil. Revista Fundação Escola Superior do Ministério Público. Brasília, v. 8, n. 5, p.93-110, jan./jun. 2000. Disponível em: < www.escolamp.org.br/ARQUIVOS/15_07.pdf>. Acesso em 15 de mai. 2017.

PORTELA. Paulo Henrique Gonçalves. Direito Internacional Público e Privado Incluindo Noções de Direitos Humanos e Comunitário. $7^{a}$ ed. São Paulo: JusPodivn, 2015.

ROCHA. Carlos Frederico. Análise do programa Michel Temer provoca arrepios. Disponível em: <http://.www.pragmatismopolitico.com.br/2016/05/analise-do-programa-demichel-temer-provoca-arrepios.html>. Acesso em 15 de mai. 2017.

SILVA. José Afonso da. Curso de Direito Constitucional Positivo. $18^{a}$ edição. São Paulo: Malheiros, 2000.

SUSSEKIND. Arnald. Direito Internacional do Trabalho. 2. ed. Rio de Janeiro: Renovar,1999.

VARELLA. Marcelo D. Direito Internacional Público. $4^{\circ}$ ed. São Paulo: Editora Saraiva, 2012. 